\title{
La definición del arte antes (y después) de su indefinibilidad
}

\author{
JUAN FLÓ \\ Instituto de Filosofía \\ Universidad de la República \\ juanflo@fhuce.edu.uy
}

\begin{abstract}
Resumen: En este trabajo se discuten algunas propuestas acerca de la definibilidad del arte (Weitz, Danto, Dickie, Levinson) para concluir que todas implican alguna forma de "institucionalismo", y dan lugar a una definición "procedimental" que carece del interés y la aplicabilidad de las auténticas definiciones. Se propone una estrategia que consiste en prescindir de las dificultades que origina la situación actual de las artes visuales, puesto que sólo se puede rechazar esa estrategia si suponemos que las últimas manifestaciones del arte revelan una dificultad que está presente también en el arte anterior. Pero esto sólo sería así si no fuera posible una definición que valiera para toda la historia previa. Se propone, entonces, una conceptuación del arte como un proceso que no posee una esencia ni se desarrolla a partir de un programa, pero que lo hace como una entidad singular, identificable, y no como una mera sucesión o conglomerado. Se discuten, entonces, las condiciones teóricas que exige esta hipótesis y los hechos históricos que la sustentan.
\end{abstract}

Palabras clave: estética, definición del arte, Duchamp

En este artículo se intenta justificar un punto de vista que difiere de las concepciones que han prevalecido en la discusión que sobre el arte, y en particular sobre su definibilidad, han sostenido los filósofos en las últimas décadas. Dado que el objetivo principal de estas páginas es presentar dicho punto de vista disidente, las referencias a algunas de las teorías más influyentes se limitarán a la mención de sus conclusiones básicas, sin considerar sus múltiples matices e intrincadas relaciones mutuas. Lo que importa aquí es determinar si las conclusiones en que ellas culminan — que excluyen, por imposible, una auténtica definición del arte- pueden ser sustituidas de manera razonable mediante un abordaje diferente. No considero auténticas las definiciones del arte que Davies (1991) llama procedural definitions, ni tampoco las que — como la que propone Danto (1997) - tienen tan indeterminada y abierta denotación que, al igual que las del tipo anterior, a fin de cuentas no hacen sino admitir las decisiones de facto del "mundo del arte". 
Me propongo discutir, entonces, algo que podría llamarse la "lógica" del concepto de arte, si no fuera porque esa denominación insinúa un tipo de planteamiento que es precisamente el que intento evitar y que, indirectamente, discuto aquí. Me refiero a que no creo fructífero analizar el concepto de arte sin prestar atención, en forma predominante, al acontecer histórico que lo fue constituyendo, a él y al objeto o los objetos a los que se refiere. En ese sentido, las dificultades que dicho concepto ha planteado a la reflexión contemporánea son una buena prueba de que los filósofos muchas veces abordan de manera poco adecuada algunos temas que requieren un tratamiento interdisciplinario, $\mathrm{y}$ un buen indicio de que frecuentemente ignoran en qué medida sus reflexiones intervienen prácticamente, legitimando o socavando un estado de cosas. De allí la relativa infertilidad de los enfoques analíticos en el terreno de la estética, infertilidad muchas veces reconocida desde posiciones próximas a esos enfoques. ${ }^{1}$

Aunque me voy a referir primordialmente a discusiones que tienen que ver con las artes visuales, creo que muchas de las observaciones valen para las artes en general. Si mi atención está dirigida a las artes visuales es, principalmente, porque a propósito de ellas se han puesto en discusión la mayor parte de los problemas que interesan a este tema. Esto es así porque la historia de esas artes, en los últimos ciento cincuenta años, ha sido particularmente instructiva y "problemática". La razón de ese privilegiado locus problemático que son las artes visuales -y que las vuelve un objeto extraordinariamente provocativo para la indagación teórica- debería ser objeto de investigación para, entre otras cosas, justificar la legitimidad de las generalizaciones que podamos hacer incluyendo las demás artes. Pero ése es un tema que no tiene cabida en este trabajo.

La reflexión acerca de las dificultades que plantea el concepto de arte es un tema que adquiere relevancia recién en la segunda mitad del siglo xx. Sin duda que, en gran medida, ello es provocado por los cambios ocurridos en las artes de este siglo; pero no dejamos de reconocer la marca de esas dificultades en toda la historia de la estética aunque en ella no aparezcan tematizadas. El concepto de arte - al igual que otros conceptos relativos a las demás prácticas sociales y a las instituciones que resultan de ellas y las encuadran- propone algunos problemas peculiares: se trata en todos los casos de actividades y/o sistemas de normas y creencias que tienen naturaleza histórica. Esto significa que se manifiestan de muy diversas maneras a lo largo del tiempo y en distintas culturas, y que están abiertos a transformaciones que no podemos prever. Lo anterior da lugar a que las prácticas o las instituciones planteen a veces, ante ciertos cambios sufridos por ellas, el problema de si se han transformado, o si, en realidad, dichos cambios significan la desaparición de una práctica y su sustitución o su-

\footnotetext{
${ }^{1}$ Isenberg 1987, Ahlberg 1993.
} 
cesión por otra. Según la respuesta que demos será necesario mantener, redefinir o sustituir el concepto correspondiente. Sin embargo, en general, la dificultad no se manifiesta porque, aun en aquellos casos en los cuales la diversidad de manifestaciones históricas vuelve discutible su identificación mediante un concepto común, disponemos, por lo menos, de uno de dos recursos suficientes: o bien podemos invocar ciertas estructuras biológicas, genéticas, que reconocemos como el fundamento común de esas prácticas, o instituciones, que tienen diversas expresiones históricas o culturales, o bien podemos indicar ciertas funciones que pueden cumplirse de diversas maneras y a través de manifestaciones diferentes, pero que aseguran la identidad (o mejor, la identificación) de la práctica a la que hagamos referencia. Es decir, disponemos - como ocurre con el concepto de familiade un determinado conjunto de notas que tienen, hasta cierto punto, una estabilidad asegurada por condiciones preculturales que se anclan probablemente en el equipo innato del sujeto. O, como ocurre con el concepto 'actividad económica', podemos remitirnos a un conjunto de prácticas muy diversas que son pensables como denotata de un concepto cuya nota esencial radica en una función común a todas ellas.

Está claro que, aun en estos casos, el concepto se refiere a un proceso en el cual nunca es posible estar seguro de que las modificaciones futuras no nos planteen problemas serios; por lo menos el problema de decidir, en cierto momento, si seguimos frente a la misma entidad cuando ha habido cambios significativos, pero dentro de cierta continuidad (por contigüidad temporal, al ocupar sucesivamente un cierto espacio social; o por causalidad, en cuanto producto de la situación anterior; o por el mantenimiento de un conjunto de notas compartidas con la situación anterior; o por la suma de todos o algunos de esos factores). Porque no importa cuán precisa sea la identificación de cierta práctica, tanto en el caso de que se trate de un concepto que se define por un patrón básico (aunque modificable) de origen precultural, como en el caso de que se defina por la función, lo cierto es que no podemos ignorar la posibilidad de que la práctica o la institución correspondiente puedan desaparecer. En una situación de este tipo, en la medida en que cierta práctica haya sido sucedida por otra que guarda con la anterior cierta relación (del tipo de las que indicamos antes: causalidad, contigüidad o subsistencia de rasgos comunes), la decisión no podrá sino estar fundada en la conveniencia de optar por una de dos posibilidades: referirnos a las nuevas entidades con el mismo vocablo, considerando que se refiere al mismo concepto aunque aparezca redefinido, o utilizar un nuevo término de lenguaje, entendiendo que se trata de un nuevo concepto que tiene una nueva referencia.

Lo cierto es que las transformaciones de las prácticas o de las instituciones en general no han planteado una discusión acerca de la lógica de conceptos; por ejemplo, 'religión', 'organización política', 'técnica', 'moral', 
etc., aunque sí han planteado discusiones en las zonas de borde acerca de si ciertas prácticas son religiosas o mágicas, o si ciertos objetos usados por los homínidos son herramientas o no. Pero en esos casos no se discute la posibilidad de constituir conceptos o definiciones, sino acerca del punto justo en que se pueden determinar los límites difusos que hay entre ellos, límites difusos que podemos encontrar no solamente en los conceptos que hacen a las prácticas y a las instituciones sociales, sino también en las taxonomías usadas por las ciencias naturales.

En el caso del arte, en cambio, hay fuertes dificultades para construir una definición satisfactoria, aunque esas dificultades sólo fueron discutidas explícitamente a partir de la década de los 1960 como consecuencia de la irrupción en las artes visuales del objeto vulgar "transfigurado", en el sentido en que Danto usa ese término. Hasta ese momento, el problema de la estética era, dada una denotación del concepto 'arte' que estaba fuera de discusión, descubrir una nota esencial que sirviera para definir el concepto. Pero a partir de las corrientes artísticas que en la década mencionada explotan el solitario gesto de Duchamp y lo transforman en escuela, surge un nuevo problema: la imposibilidad de definir el arte porque es imposible acotar la denotación del concepto. ${ }^{2}$

Pero las dificultades que para definir el concepto revela esa nueva situación del arte no nacen de ella, por más que sea allí donde se manifiesten. Aunque no dispusiéramos de propiedades observables que fueran necesarias y suficientes para saber si cierto objeto integra la denotación del concepto, sería posible fundar la definición en ciertas propiedades relacionales, y, en particular, según hemos visto ya, en la de provenir de una disposición innata o en la de ser instrumento eficaz para cumplir cierta función. Pero ni una ni otra de estas propiedades puede ser atribuida fácilmente al complejo y variable hecho social e histórico que es el arte. En ese sentido podemos decir que la irrupción en el arte del "objeto cualquiera" no introduce dificultades que vienen de mucho antes sino que, simplemente, las vuelve ostensibles. Pero lo importante no es que vuelva visibles viejas dificultades relativamente ocultas, sino que dé lugar a una dificultad nueva e insuperable: a partir de allí el arte se vuelve indefinible. La imposibilidad de señalar propiedades relacionales o propiedades intrínsecas (u observa-

\footnotetext{
${ }^{2}$ Es de señalar que en el mismo año y en el mismo mes se dan a conocer dos textos que postulan la inexistencia de notas esenciales que permitan acotar la denotación del concepto 'arte'. Uno de ellos es el notorio artículo de Weitz (1956) que comentaré más adelante. El otro, presentado en el Terzo Congresso Internazionale di Estetica (Venecia, septiembre de 1956), sostiene que "il n'y a pas une spécificité de l'objet esthétique. La simple évaluation peut fonder l'objet esthétique comme tel" ["no hay especificidad del objeto estético. La simple evaluación puede fundar el objeto estético en cuanto tal"], y también que "L'objet esthétique est un acte de foi culturelle" ["el objeto estético es un acto de fe cultural"] (Fló 1957). Morawski, varios años después, transcribe esta última cita pero la entiende equivocadamente, como si sólo expresara un relativismo cultural (Morawski 1974).
} 
bles) que permitan una definición del arte no es lo mismo que admitir que se incluya en la denotación del concepto lo que antes estaba explícitamente excluido de ella. Esa decisión comporta una ruptura que replantea el problema en otros términos: a partir de ella, el arte no solamente es de difícil definición por el hecho de que no podemos acotar su denotación mediante propiedades observables de los objetos ni por la función o el sustrato biológico de la actividad, sino que, a partir de dicha decisión, no existe entidad o evento que pueda ser excluido del universo de los candidatos a obra de arte. Puede decirse que esa admisión del objeto común -o del objeto cualquiera - como parte de la denotación del concepto no sólo vuelve imposible toda definición en términos esenciales, sino que, además, es también algo así como la instauración de las condiciones que sirven para sustentar una definición institucionalista.

No creo que la mutación del arte contemporáneo sea lo que nos revela la naturaleza del arte y nos permita, por fin, superar las viejas teorías; por el contrario, creo que supone una ruptura tan radical con la historia previa del arte que considerar que sus productos deben ser denotados por el mismo concepto bloquea necesariamente la posibilidad de definición. De todos modos, sostengo que esa mutación nos permite comprender mejor la historia de lo que llamamos "arte", pero a condición de no intentar que esa comprensión tenga el objetivo de llegar a una definición que incluya al mutante. Y pretendo mostrar que solamente si no quedamos apresados en el problema de una definición del arte que busque incluir la "transfiguración del objeto común", podremos alcanzar una comprensión del modo como se constituye y desarrolla el arte: como práctica, como producto y como concepto. Solamente entonces podremos, a la vez, obtener una definición (o una identificación) del arte, y comprender el surgimiento de ese mutante al que, de modo estrictamente convencional, podremos mencionar con el mismo o con otro término de lenguaje. Y también podremos plantearnos de manera razonable si ese mutante ha cancelado la vieja historia del arte y si queremos o no que ello sea así.

A condición de mantener esa estrategia, considero posible definir el arte (o identificarlo) sin incurrir en una definición "procedimental", como lo hace Dickie, o en un enfoque que también lo es - aunque se presente como esencialista e historicista a la vez- como el que aventura Danto.

En 1917 Duchamp intenta exhibir su famoso urinario. Sólo cuarenta años después Weitz (1956) niega que se pueda definir el concepto de arte, sin mencionar ese hecho histórico y como si sus reflexiones fueran independientes de la historia del arte. Su tesis principal es que es lógicamente ilegítimo tratar de hallar las notas necesarias y suficientes del concepto 
'arte' porque se trata de un concepto abierto, respecto del cual es posible señalar algunas condiciones bajo las cuales se puede aplicar correctamente, pero no hacer la lista de todas ellas porque siempre es posible que se den nuevas condiciones. Está claro que tal situación es la propia de los conceptos que no pertenecen a una teoría del tipo de las que construyen y definen completamente sus conceptos (es decir, las ciencias formales), según lo indica el propio Weitz. En todo caso, podemos extender esa posibilidad a todas las instancias en las que disponemos de lo que Kripke (1981) llama designadores rígidos.

Aunque Weitz no lo dice así, y parece dar por supuesto que es suficiente con atribuir al concepto 'arte' el carácter de concepto abierto, debemos inferir que, en su caso, lo importante no es que se trate de un concepto abierto, sino el modo de su apertura: ella no proviene del hecho de que aprendemos nuevas cosas acerca de una realidad presuntamente estable y reformamos un concepto que se refiere a lo mismo (como lo hacían los químicos del siglo XIX cuando descubrían nuevas propiedades de ciertos elementos, o como lo hacían los naturalistas del XVIII al averiguar que los delfines son mamíferos). En el caso del arte, el concepto es doblemente abierto porque no solamente es abierto su sentido, sino también su referencia, y esto como resultado de una producción humana que no se rige por normas invariables que determinen las propiedades observables ni los significados de sus productos. En el caso de un concepto reformable, la identificación del objeto no es difícil; en el caso de un concepto que cambia su referencia, esa identificación aparentemente se vuelve arbitraria.

De lo anterior surgen algunas consecuencias importantes. La primera es que debemos llegar a una conclusión que Weitz no termina por admitir claramente, a pesar de que en algún momento dice que frente al surgimiento de nuevas obras, los interesados, en particular los críticos, deben tomar la decisión de si algo es o no una obra de arte. Esa conclusión es que la identificación del objeto tiene un carácter puramente decisorio, de facto, lo que, a fin de cuentas, hace que el arte sea simplemente lo que de manera tradicional se sigue llamando tal, o lo que ciertas autoridades llaman "arte", y en ese sentido esté prefigurando lo sustancial de la teoría institucionalista.

Una segunda observación es que el surgimiento de nuevas obras de arte nunca puso en tela de juicio la posibilidad de definir el arte. Y esto no solamente porque entre lo que ahora llamamos artes hubo extensísimos periodos de arte canónico, sino, además, porque en toda la época moderna, hasta la segunda década del siglo Xx (en la cual la búsqueda de lo personal, de lo original y de lo nuevo fue ensanchando la libertad de creación, y estimulando el rechazo a toda norma y a toda preceptiva), no hubo ninguna pretensión de proponer como obra de arte algo que fuese otra cosa que lo que nacía como una obra de arte. Es decir, a nadie se le habría 
ocurrido considerar como arte algo que, al margen de las dudas que pudiera merecer su calidad y del rechazo a que diera lugar su extravagancia, fuera un objeto de naturaleza distinta promovido a la categoría de obra de arte como resultado de una propuesta y, eventualmente, un contexto o la elección de un punto de vista. No es cierto que, como dice Weitz, el hecho de que el arte sea una producción humana abierta, no regida por norma, y que tenga un very expansive, adventurous character, determine necesariamente la imposibilidad de una definición. La definición se vuelve imposible solamente cuando ese carácter expansivo y aventurero llega a llamar arte a un objeto que, previamente a esa decisión, era simplemente otra cosa. Y aunque Weitz no cita a Duchamp (y de ese modo da un aire intemporal a su análisis), pone, sin embargo, el ejemplo de algo que podría ser considerado dentro del campo del arte, algo que ni siquiera es un artefacto: un simple leño arrojado como resaca por la marea (a piece of driftwood). Está claro que, para que el ejemplo le resulte admisible, el lector tiene que haber sido educado por los ready made de Duchamp y por los objectes trobats de Miró.

En este punto estoy sosteniendo que solamente en la situación anómala que surge en la segunda década del siglo xx es posible plantear una tesis como la que señala Weitz. Reitero que en tanto que las dificultades propias del concepto 'arte' no son incompatibles con una definición (o por lo menos con una forma de identificar el arte desde la cual sea posible argumentar en el sentido de si una obra es o no una obra de arte), a partir de lo que podemos llamar el "efecto Duchamp" (o "efecto D"), esto ya no es posible; ocurre un corte de tal naturaleza que decidir si algo es o no es arte es solamente resultado de un uso impuesto por una convención establecida por razones de conveniencia o de poder. Si lo expresamos en términos que permitan utilizar algunas de las fórmulas que han tenido fortuna en estos últimos años, adelanto que desde la concepción que aquí se defiende hay efectivamente un arte "posterior" a la historia del arte, pero que, a diferencia de lo que sostiene Danto (1997), ni está claro que esta historia haya llegado a un fin -en el sentido de que allí llegó a sus límites (the pale of the history) - , ni es cierto que sea necesario, legítimo, o siquiera conveniente, que el arte que sucede al que llegó a ese presunto fin sea considerado denotable por el concepto 'arte'.

De todos modos, la tesis de Weitz es consistente en la medida que podamos leerla como el momento precursor del institucionalismo; esto pudo no ser visto con claridad en su momento, pero está presente en su artículo de manera explícita: "new art forms, new movements will emerge, which will demand decisions, on the part of those interested, usually professional critics, as to whether the concept should be extended or not" ["surgirán nuevas formas de arte, nuevos movimientos, los cuales exigirán decisiones, de parte de los interesados, normalmente críticos profesionales, respecto de si el concepto debería extenderse o no"] (p. 32). 
En el marco de esa concepción, el uso de la imagen wittgensteiniana del "parecido de familia" solamente restringe el carácter autoritario de las decisiones: en cierto modo, los críticos quedan amparados por el hecho de que existen similitudes y también limitaciones por las cuales la ampliación del concepto no es absolutamente libre. Está claro que ese recurso al parecido de familia tiende a oscurecer la idea central, entre otras cosas por la observación hecha en su momento por Mandelbaum (1965) - y reiterada muchas veces por otros autores-, en el sentido de que el parecido de familia es un parecido cerrado dentro de una clase en la cual hay lo que podríamos llamar un principio de definición esencial (el genoma). ${ }^{3}$

Para expresar más claramente su núcleo duro, la tesis de Weitz no debería haber apelado a algo que no sólo muestra la apertura del concepto, sino que también sugiere un universo previamente acotado; debería decir más enérgicamente que ese cierre es solamente de facto, solamente producto de decisiones, y asumir las consecuencias. Esas consecuencias no son menores, ya que el concepto 'arte' se vuelve una convención léxica, y la existencia de rasgos comunes sólo indica vagamente cuál es el mecanismo que, a través de una historia del uso de un término, o a través de cierta forma de decisión o convención, da lugar a que se amplíe la denotación de un concepto.

Aunque Dickie publicó su libro clásico (Dickie 1984) casi tres décadas después de que apareció el artículo de Weitz, creo que lo continúa mediante un doble movimiento respecto al punto en el que el problema fue abandonado por este último. Por un lado explicita y articula la tesis más fuerte de Weitz, en el sentido de la amplitud del concepto y los mecanismos de su ampliación. Por otro lado, aparentemente, difiere de la que parece ser la tesis más ostensible de éste, a saber, la indefinibilidad del arte. En realidad, en Weitz la indefinibilidad y la convencionalidad del concepto son la misma cosa. Así, en la medida en que Dickie pasa el segundo de los términos a primer lugar, le es suficiente con proponer un tipo de definición que simplemente describe el modo como la denotación del 'arte' se constituye de facto, para poder llamar "definición" a lo que para Weitz era precisamente la prueba de la indefinibilidad. Pero, en sustancia, los dos términos se refieren a una realidad equivalente, y lo cierto es que el término 'definición' es el que se usa con referencia y sentido diferentes.

Es interesante notar que la reconstrucción que hace Dickie de Weitz implica reconocer en el artículo de éste la presencia del punto básico de su propia postura. Si, como dice Dickie (1984, p. 31): "Noted similarity and calling something 'art' are for Weitz, sufficient for making that something art" ["Advertir la similitud y llamar a algo 'arte' son suficientes, según Weitz, para hacer de ese algo arte"], esto significa que para Weitz el ser denominado arte es una de las dos condiciones que hacen que algo lo sea,

${ }^{3}$ Objeción que vale también para el uso que hace Wittgenstein de ese recurso. 
y esta afirmación es, a fin de cuentas, el núcleo de la tesis institucionalista. Por otra parte, para Dickie, la similitud de algo con lo previamente llamado arte resulta un rasgo que no puede invocarse como parte de la definición, pero sí lo es, en cambio, la condición de ser un artefacto, es decir, un producto de la actividad humana (dos cosas que Dickie vincula, y que sustenta mediante una argumentación compleja que no voy a discutir aquí). Pero el carácter de ser artefacto no excluye ni el ejemplo de Weitz de un trozo de madera arrojado por el mar, ni el urinario de Duchamp. La tesis de Dickie es que el acto de elegir algo como arte y presentarlo como tal es una manera de producir, de hacer.

Aunque no quiero discutir los detalles, no puedo dejar de plantear una objeción que creo importante a esa exigencia de "artifactualidad". Efectivamente, lo que aparece como una condición agregada que limita el carácter convencionalista de la teoría no es tal cosa, porque la propia condición de "artifactualidad" es, ella misma, el resultado de una decisión taxonómica y puede reducirse a ella: la de presentar como arte cualquier objeto.

En otras palabras, el carácter de artefacto y la presentación de ese producto ante el mundo del arte (que lo recibe y lo denomina como tal) constituyen la definición que Dickie propone. Por lo tanto, como la presentación puede ser toda la artifactuality requerida, todo lo que se necesita como notas que definen el concepto es la presencia de dos actos de decisión: el individual y el institucional.

La propuesta de Dickie, aunque intuitivamente chocante, debe ser valorada como un esfuerzo consistente y elaborado. Según lo dice explícitamente (1984, p. 110), lo que se propone es alejarse de las obras individuales y conseguir la suficiente distancia que nos permita considerar la miríada de objetos (algunos triviales, otros de la mayor importancia) que han sido interpretados con diversas teorías, cada una de las cuales ha entrevisto un aspecto de lo que el arte puede ser. Más precisamente: "What institutional theory does try to do is to describe the human practice of creating and consuming art." ["Lo que la teoría institucional sí trata de hacer es describir la práctica humana de crear y consumir arte"] Por otra parte, esa práctica está definida — señala Dickie- de tal manera que permita preservar la libertad del arte futuro. Queda claro que la inevitable consecuencia de esto es que tal definición no nos permite extraer de la teoría la menor indicación, fundamento o atisbo, de lo que podemos proponer, aceptar o estimar como arte futuro. En la medida en que se limita a acatar el poder instaurador del mundo del arte y sus decisiones, y nada agrega a ese respecto, no puede ser utilizada en el mundo del arte, salvo como una legitimación universal, y para siempre, de sus decisiones, al precio de que esas decisiones queden privadas de todo apoyo por parte de la reflexión filosófica. Éste es un costo alto para el mundo del arte, el cual recibe legitimación absoluta a cambio de un total desamparo por parte de la filosofía; y un costo muy alto para 
la filosofía que consigue el tour de force de definir los productos de cierta práctica humana sin que ese conocimiento pueda intervenir en esa práctica como fundamento - o parte del fundamento- de sus decisiones.

Más aún, podemos argumentar que una postura como ésta, al mismo tiempo que parece legitimar las decisiones del mundo del arte, en último término las deslegitima, porque permite descubrir en estas decisiones una operación fraudulenta. El mundo del arte, para Dickie, está constituido por diversos roles pero, en particular y como núcleo, por el rol que desempeñan los artistas y el público. Al no analizar el modo como el público constituye su opinión en esa descripción se ignora que la decisión proviene de quienes tienen cierto poder específico para la imposición de valoraciones, y cuya capacidad de persuasión se basa en un discurso argumental. Solamente si ese poder se ejerciera de una manera despótica o mediante formas de persuasión completamente irracionales, de tal manera que no pretendiera convencer de manera argumentativa, no habría colisión entre la teoría institucionalista y la institución misma. Pero si no partimos de esa acción despótica, o, en su defecto, de una seducción incantatoria de la palabra crítica, nos enfrentamos a una disyuntiva inevitable: o se infiere de la teoría que las argumentaciones son meras simulaciones que persuaden por vías no racionales, o esas argumentaciones tienen cierto valor. Si lo primero, la teoría institucionalista es consistente, pero ella no puede ser aceptada por el mundo del arte, tal como está constituido, porque deslegitima su modus operandi. Si lo segundo, la teoría desconoce el verdadero sentido de las apreciaciones del mundo del arte, a las que considera solamente decisiones de facto, y se abre, entonces, la posibilidad de una definición del arte que no sea solamente "procedimental" (aunque es cierto que todavía hay una tercera posibilidad, que valdría la pena explorar en otro momento, que consiste en considerar que la obra de arte no es el objeto que produce el artista, sino aquello que produce el crítico bajo la forma de un discurso hipnótico y seductor. Es la función que, de hecho, han asumido, en las últimas décadas, muchos críticos y muchos curadores de las grandes muestras internacionales).

Vale la pena recordar, por otra parte, que aunque la investigación de Dickie es un esfuerzo elaborado de análisis filosófico, su objetivo final coincide con el de una investigación sociológica que seguramente alcanzaría resultados parcialmente similares, pero que sin duda podría agregar algunas conclusiones interesantes acerca del funcionamiento del mundo del arte. Es lo que en otro registro hace Bourdieu (1987), quien concluye algo que se parece bastante a la teoría institucionalista, pero por esa vía puede atribuir al arte algunas funciones que, aunque no creo que sean las específicas, describen muy agudamente algunos de sus usos sociales.

La renuncia de Dickie a que la filosofía haga algo más que entregar los problemas del arte a las ciencias sociales es muy visible en sus últimos 
escritos en los que su propuesta se presenta como la alternativa a teorías que consideran que el arte depende solamente de mecanismos psicológicos innatos, teorías a las que llama teleológicas. Al quedar el arte, para Dickie, desprovisto de toda raíz psicológica innata, éste puede ser concebido como una producción puramente convencional, ya que una obra de arte resulta ser tal solamente por la red de relaciones culturales que la envuelven (Dickie 2001, p. 23). Pero no es suficiente con ese culturalismo inusitadamente radical, puesto que, para que de esa premisa se pueda concluir la teoría institucionalista, es necesario otro supuesto no explicitado por Dickie: que esas relaciones culturales solamente pueden ser explicadas, cada una de ellas, como un acontecer ocasional, como un conglomerado que resulta de un haz de series causales independientes. De este modo no puede existir una especificidad cultural que pueda ser definida como arte.

Unos años antes de los escritos de Dickie y algo después del texto de Weitz, había aparecido un artículo de Danto (1964) que se volvió célebre. Ese trabajo tiene una virtud que, sin embargo, por el modo como ella se ejerce, exhibe la principal debilidad que la aqueja. Me refiero a que la apelación a la historia por parte del filósofo nos revela el fuerte riesgo de que la historia de que éste se sirve, y que parece dar un sustento empírico a sus teorías, no sea otra cosa que la historia que le es sugerida por sus teorías, o que simplemente cuadra con ellas. Y no basta con decir que "las complejidades de la historia deben ceder ante [must yield before] las exigencias de la exposición lógica", como dice Danto. Algunas de esas simplificadas y, en mi opinión, inadmisibles interpretaciones acerca de la historia del arte y acerca del pensamiento que, según Danto, orienta esa historia, serán parte esencial de sus reflexiones a lo largo de los siguientes veinticinco años. Ya en su artículo mencionado hay algún ejemplo aleccionador y típico de una lectura de la historia de las artes visuales que parece hecha por un teorizador que conoce la pintura sólo a través de meras descripciones verbales.

No corresponde ahora considerar la extensa producción de Danto y estudiar el desarrollo de su pensamiento. Sólo voy a considerar sus teorías mediante el expediente de revisar su artículo precoz a la luz de sus libros posteriores más significativos (Danto, 1981, 1986, 1997). A partir de lecturas de las obras de arte como ejemplificación de ciertas teorías, Danto reconstruye una historia que, según él, se acelera en el último siglo, en la que el arte se expresa como la manifestación de ciertas teorías que suceden a la teoría mimética de larguísima vigencia. En la segunda mitad del siglo $\mathrm{xx}$, el pop empuja el arte a poner en tela de juicio todo criterio para diferenciar la obra de arte del objeto común. En ese sentido, según Danto, el pop nos pone ante una situación privilegiada desde el punto de vista de la filosofía, una situación en la que, por fin, estamos en condiciones de entender el arte más allá de las restrictivas teorías que estuvieron unidas 
a estilos históricos particulares. Ahora, concluye Danto, estamos en condiciones de acceder a una nueva teoría que no es simplemente, como las anteriores, la legitimadora de ciertas escuelas o estilos.

Para ejemplificar el tipo de lectura que le permite transformar los problemas de la pintura en problemas de tipo teórico - con lo cual la pintura parece ser, para decirlo a la manera de von Clausewitz, algo así como la teoría proseguida por otros medios- basta con señalar que el uso no realista del color en los fauves es entendido por Danto como un modo de expresar en el cuadro el rechazo a la teoría mimética del arte; algo así, según él mismo lo dice, como un billete falsificado de manera impecable, que llevara un sello que nos informa que se trata de una falsificación que no tiene curso legal. Obsérvese que esta imagen no es un ingenioso recurso expositivo, sino que es sintomática de su modo de identificar la pintura más visual con la pintura más conceptual. Así es como interpreta las refinadas osadías cromáticas de Matisse (que producían la envidia de Picasso) con una operación lógico-semántica que recuerda los conocidos juegos de Magritte con su famosa pipa, o los juegos verbo-visuales de los conceptualistas. De ese modo aniquila las diferencias entre una pintura brutalmente visual y los modos visuales de ilustrar el concepto o el ingenio.

Con este expediente sencillo, Danto consigue interpretar la historia del color en la pintura a fines del siglo XIX y principios del XX, no solamente como el abandono de la fidelidad realista al color local — que ya había sido amenazado por las experiencias del impresionismo en nombre de otro realismo-, sino como un instrumento semántico con el cual cierta pintura expresa su ruptura con una teoría previa. En esa historia parece que no desempeña ningún papel el hallazgo del poder expresivo del color vinculado a la figuración en el que todos sus ingenuos admiradores creímos siempre. Un poder que, para poner un ejemplo no desdeñable, deslumbró a von Hofmannsthal (1901) cuando llegó casual y desprevenidamente a una exposición de van Gogh, sin tener la menor noticia de quién era ese pintor, ni de que era posible pintar de ese modo.

Solamente una experiencia muy restringida del arte (hablo de una experiencia, no de un conocimiento intelectual) a lo largo de su historia puede ignorar las diversas modalidades que pueden ser reconocidas intuitivamente (lo que no quiere decir sin entrenamiento) de la invención visual. Y sólo así se puede ignorar que esas cualidades se fueron volviendo cada vez más ostensibles a medida que ciertos problemas propios de la invención pictórica —que no son parte intrínseca del proyecto mimético, pero que lo acompañaron siempre- se volvieron protagónicos. Es evidente que esa historia exige una recepción especial, entrenada, capaz de reconstruir la condiciones de la producción de ese arte, e incluso capaz de superar las formas comunes de recepción, llena de equívocos y malentendidos que son, sin embargo, los que aseguran la vida social del arte. La reconstrucción 
que hace Danto de esa historia es una manera de simplificar y transformar las claves del arte visual en algo accesible a los ciegos y a todos los que carecen del entrenamiento necesario para acceder intuitivamente a productos de una gran complejidad, que sólo son reconocibles en su peculiaridad por una experiencia cualitativa. Para Danto, los cambios del arte se vuelven meros cambios de teoría que rigen un modo de interpretación. Las cualidades vividas quedan reducidas a formas aparentes o inducidas por las interpretaciones, y, a fin de cuentas, ellas dependen de las teorías que las generan y las justifican. Si llevamos el punto de vista de Danto a sus últimas consecuencias, podemos decir que si estamos en condiciones de manejar conceptos, ya estamos, entonces, en condiciones de mirar el arte, limitándonos al interés intelectual que tiene reconocer la teoría que cada corriente ejemplifica. En realidad, desde una actitud como la de Danto podríamos ahorrarnos la frecuentación del arte: a fin de cuentas, el arte parece ser solamente una visualización pedagógica, al uso de los no filósofos, de las ideas acerca de arte.

Está claro que, para una concepción de este tipo, la historia del arte como un proceso de reconocimiento conceptual de sí mismo se expresa de manera terminal en el pop. Con el pop, el arte muestra que es solamente interpretación, y también muestra que todas las corrientes, estilos y teorías del pasado partían de supuestos que es momento de abandonar. Todo estilo estuvo asociado a una teoría restrictiva, y todas las teorías supusieron que en las artes visuales la calidad de ser un objeto de arte no puede ser ajena a sus cualidades sensibles. Para Danto, a partir de la autoapropiación filosófica que el arte adquiere con el pop, se acabaron las restricciones de las teorías propias de un estilo, y el arte no es definible por sus propiedades intrínsecas, sino por el hecho de ser interpretado como tal por "el mundo del arte".

El pop permite que el simple y terco hombre común no pueda distinguir entre arte y realidad. De esta manera, el pop nos pone de nuevo ante la pregunta que Weitz consideraba incontestable, porque en lugar de disponer, para responderla, de una teoría que nos dé un criterio (la teoría de la mimesis, o la de la expresión, o la de la creación de una realidad independiente que se suma a la realidad), ahora nos encontramos con que ya no podemos establecer una distinción entre realidad y arte que no esté basada en el principio de que la obra de arte es algo que requiere un "mundo del arte" que decide mirar cierto objeto como abierto a una forma de interpretación ("the is of artistic identification") que es propia de la obra de arte, y que es necesario dominar para reconocer la diferencia entre una cama real y la obra de Rauschenberg.

Todo esto parece decir que siempre el arte fue el resultado de interpretaciones legitimadas desde cierta teoría, pero que, en el presente, se acabaron las teorías legitimadoras. Ahora el mundo del arte vuelve el arte 
pura interpretación. Pero está claro que si la interpretación queda abierta, entonces, o reconocemos la absoluta libertad de interpretación (cosa que Danto niega sin que sepamos con qué argumentos, puesto que solamente afirma que "There are, of course, senseless identifications" [Hay, desde luego, identificaciones sin sentido"]), o debemos atribuir al mundo del arte el poder de establecer el derecho a que algo pueda ser objeto de interpretaciones del tipo de las que la obra de arte admite. ${ }^{4}$ Pero entonces es cierto que Danto es un precursor de la teoría institucionalista, como lo cree Dickie reconociéndole esa precedencia, aunque Danto lo haya negado (Danto 1981, p. VIII y pp. 91-95). Posteriormente Danto se distancia radical, pero fugazmente, del institucionalismo atribuyendo a la historia del arte algo parecido a una dirección: adopta una inspiración hegeliana, reconoce su historicismo y da por sentado el fin del arte y el comienzo de una nueva situación peculiarísima. Esa postura -que es, creo, la más consistente, y quizá compartible, concepción asumida por Danto- asoma apenas al final de uno de sus trabajos más difundidos, en el que formula su visión de una utopía que hace que el arte pase a ser un acto de libertad del sujeto singular: "As Marx might say, you can be an abstractionist in the morning, a photorealist in the afternoon, a minimalist in the evening. Or you can cut out paper dolls or do what you damned please" ["Como Marx pudo haber dicho, usted puede ser abstracto por la mañana, realista fotográfico por la tarde y minimalista por la noche. O bien puede recortar tiras de muñecos de papel o hacer lo que se le antoje"]. Y pocas frases más adelante agrega: "The institutions of the artworld — galleries, collectors, exhibitions, journalism - which are predicated upon history and hence marking what is new, will bit by bit wither away" ["Las instituciones del mundo del arte - galerías, colecciones de obras de arte, muestras, periodismo-, a las cuales se ha atribuido, a lo largo de la historia y hasta el día de hoy, señalar lo nuevo, poco a poco decaerán hasta desaparecer"] (Danto 1986, pp. 114 115).

Una situación en la que el arte desaparece como institución, se transforma en un ejercicio individual, no se diferencia de un juego idiosincrásico, está indeterminadamente abierto, y es indefinible, es una situación en la que desaparece como arte y se parece más a las condiciones protosociales que pueden estar en las raíces del arte. Y es cierto que se trata de una situación que podemos representarnos como posible y puede estar prefigurada por el estado actual del arte, aunque sabemos que un final como ése tiene en su contra el poder de autorreproducción que tiene toda institución. Asimismo, está claro que mal puede profetizarse el destino del arte separado de la compleja trama que lo integra en la sociedad.

\footnotetext{
${ }^{4}$ En el lenguaje de Danto en este artículo (que luego abandonará), esto consiste en esa peculiar forma de interpretar una obra que es la artistic identification, ya mencionada, concepto nada claro y que no discutiré aquí.
} 
Un tema diferente es el de si tenemos razones suficientes para descartar una perduración del arte que se suelde con la historia anterior, en lugar de escindirse de ella. Y queda abierta la tarea de definir el arte en su parábola histórica, al margen de su desaparición como tal. Un buen consejo en relación con esa tarea que surge de la fugaz profecía de Danto es que no debemos dejar que el proceso de extinción del arte agregue dificultades no pertinentes a las auténticas dificultades que tiene la definición del concepto. Pero el hecho es que Danto no insiste en esta propuesta, sino que, por el contrario, se incorpora a las instituciones del arte como crítico, lo que no parece una buena forma de disolverlas.

Por otra parte, en su libro de 1997, ni el historicismo ni el esencialismo (que Danto también sostiene y considera compatible con el historicismo) son suficientes para evitar que su teoría no implique, en último término, una postura institucionalista en el sentido lato en el que uso el término para denominar toda teoría que considera la denotación del concepto "arte" como un conglomerado de facto, resultado de decisiones o usos. La definición del arte como embodiment of meaning [corporización del significado] (Danto 1997, pp. 194-195) es tan extremadamente vaga, y, además, tan ajena a todo criterio de aplicación, que todo aquello que se pueda identificar como entidad o suceso puede, a su vez, ser producido e interpretado como caso al que se aplique tal propiedad, y nos enfrenta, así, con una disyuntiva teórica insoslayable: o adoptamos la solución de abandonar el arte a la decisión individual en cuanto juego idiosincrásico que somos libres de realizar o no, al margen de reconocimientos sociales o corporativos, o aceptamos la mera situación de facto de una institución legitimadora. La primera solución fue esbozada por Danto sólo en una ocasión (en el texto citado antes), pero es incompatible con el sustento del canon posmoderno, con la legitimación de la crítica y la curaduría de los grandes eventos, y con la propia práctica de la crítica de arte que Danto ejerce. La segunda, la institucionalista, no es asumida por el autor, pero es la única posibilidad consistente con las tesis más fuertes que él sostiene.

Por otra parte, tampoco podemos apelar a los ejemplos para darle sentido a la definición de Danto. Es imposible elegir ejemplos de lo que llamamos "corporización del significado" si no disponemos de una tradición que nos proporcione no tanto un canon, como, sobre todo, las claves necesarias para sintonizar con las obras heredadas. Rota la tradición, definir el arte como embodiment of meaning es un recurso aplicable a todo objeto que construimos como algo susceptible de interpretación. Se podría aprender en el arte anterior de qué se trata esa corporización (como lo hace Danto en algún momento (1981, cap. 7)) sólo si ese pasado fuera accesible; pero un pasado no es accesible si una continuidad de sentidos no nos habilita para leer apropiadamente los meros objetos que perduran en los museos. El modo como Danto estima que el arte actual dispone del arte del pasado 
(modo externo que solamente permite citarlo en las obras actuales mediante parodias o referencias iconográficas) indica que, actualmente, los artistas no disponen verdaderamente de él sino para mencionarlo por los rasgos más exteriores de las obras. De esos objetos que Danto define como embodiment of meaning disponen apenas de los cuerpos: los meanings originales se han evaporado. Hace ya bastante tiempo que Les Levine (1969) negaba todo sentido a cualquier tradición: inspirándose en una frase de Duchamp, afirma a que el arte muere cada treinta años.

Hay un uso diferente de la historia, más próximo a los problemas de definición, que dejó planteado Weitz. Levinson $(1979,1989)$ presenta una teoría que considera no institucionalista, historicista e intencionalista, que resume en la tesis de que una obra de arte es una cosa que ha sido "intended for regard-as-a-work-of-art, i.e., regard in any way preexisting art-works are or were correctly regarded" ["presentada para que se la estime como una obra de arte; esto es, para que se la contemple en cualquiera de las formas en que acertadamente se contemplan o se han contemplado otras obras de arte preexistentes"] (Levinson 1989, p. 21). Es interesante ver cómo aquí convergen tres posturas, en general independientes, a los efectos de que sus fuerzas se sumen para resolver el intratable concepto de arte: una postura intencionalista (que define el arte por el propósito de su productor), una postura que, como las institucionalistas, preserva una apertura ilimitada, y una concepción historicista que quiere que esa historia se articule de una manera no puramente aleatoria.

Voy a dejar de lado las múltiples objeciones de que fue objeto esta propuesta, muchas de ellas de consideración. Pero voy a proponer, por mi parte, una objeción que, por su carácter histórico, puede ser mortal para una teoría que se propone como historicista. Esa objeción se funda en el hecho de que, a lo largo de la historia, la manera de considerar la obra de arte, por lo menos en su modo manifiesto, tuvo una forma muy ajena a los modos en los cuales se expresa la intención estética en el siglo XX, justamente en el momento en el cual el concepto de arte se universaliza y, a la vez, hace crisis la posibilidad de su definición. Y esto significa que la propuesta de la vanguardia modernista no se formuló en términos de la continuidad de un reconocimiento, sino en términos de rescatar una manera escondida de manifestarse la continuidad del arte. Esto es lo mismo que decir que la continuidad fue interpretada desde cierta teoría que creía posible una definición, en lugar de haberse realizado por la transición progresiva de reconocimiento en reconocimiento. ${ }^{5}$

Pero, al margen de la objeción mencionada —que podría sortearse observando que ésa es justamente una situación especial en la que se produce el reconocimiento del arte en toda su historia, pero sin compren-

\footnotetext{
${ }^{5}$ Algo diré más adelante sobre la necesidad de proponer un término teórico especial, el de "concepto práctico", para reconstruir la continuidad histórica del concepto.
} 
der el modo como se fue construyendo la continuidad que permite ese reconocimiento-, hay que señalar el principal interés de la teoría y su debilidad mayor. El interés radica en la intención de encontrar en la historia un modo de reproducción del concepto, es decir, una filiación como la que Mandelbaum señalaba como propia del parecido de familia wittgensteiniano, y que le reprocha a Weitz no haber tenido en cuenta. Su debilidad es que el tipo de filiación, que resulta de una continuidad de las propuestas artísticas y de la recepción de las mismas, no hace de la identidad del proceso nada más que un mecanismo de facto que, en ciertas condiciones, puede darse por procesos de tradición y costumbre en los que no intervienen razones ni argumentos; en otras, pueden ser el resultado de debates, aparentemente argumentales, que en realidad expresan simples fuerzas, y, todavía en otras, puede expresar simplemente el poder de una autoridad estatal, corporativa o lo que fuere. Alguien utilizó la imagen de la cuerda larga integrada por fibras cortas como un modo de explicar el mantenimiento de una identidad en un objeto que se constituye como una continuidad formada por el relevo de elementos discontinuos. Pero utilizar este símil para el caso del arte es tan engañoso como usar el símil del parecido de familia. El parecido de familia no ocurre como resultado de una sucesión de relaciones causales diversas que conectan sucesivos sucesos o entidades, sino que es el resultado de ciertos genomas, que preexisten y determinan la aparición de los rasgos similares. En lugar de ser una conceptuación abierta, opuesta al tipo de definición esencialista, podríamos decir que nos manejamos con ella como una forma imperfecta de reconocer la aparición de cierta esencia, es decir, de una combinación de genes de cierto tipo que dan lugar a cierto fenotipo que se reitera. Lo mismo ocurre con la cuerda larga hecha de fibras cortas, ya que la expansión de un concepto por similitudes parciales de cierto objeto con otro y de éste con otro, a través una diversa similitud, etc., no es representable por una sucesión ordenada según un programa -que en el ejemplo de la cuerda consiste en la secuencia lineal-, sino que, en todo caso, podría ser representado como un amorfo volumen de fieltro que se expande en cualquier dirección, de manera aleatoria. La cuerda es posible por el orden que asumen esas fibras, y en ese sentido también allí la identidad está asegurada por una previa "esencia" que es el proyecto que dirige su fabricación. También en ella la identificación de la entidad nos está asegurada por una propiedad esencial.

Si miramos en su conjunto la discusión sobre el concepto 'arte' que se ha realizado a lo largo de estas décadas, y de la que hemos considerado velozmente algunos momentos conspicuos, vemos que, pese a su laboriosa argumentación, ha encallado en un problema difícil cuyo planteamiento le ha sido sugerido por la situación de las artes visuales a partir del efecto D. Pero como no disponía de una teoría aceptable para el arte anterior, se 
dio por supuesto que esta nueva situación del arte era precisamente la que revelaba la indefinibilidad de su concepto y el carácter convencional de la denotación de dicho concepto en toda la historia.

Creo, por el contrario, como ya lo he adelantado, que la forma adecuada de atacar el problema es considerar, en primer lugar, los problemas que plantea el concepto de arte prescindiendo del efecto D. De otra manera estaríamos implicando ya sea un supuesto que podríamos llamar de máxima obediencia (en el sentido de que aceptamos que algo es según lo denomina quien tiene de hecho el poder de imponer una denominación) o —extraña alternativa - un supuesto hegeliano: que la historia del arte es la historia de la progresiva revelación de su concepto. Ese último supuesto está explícito en Danto y está implícito en la lectura que hace Bürger (1974) de Marx.

\section{III}

El concepto 'arte', como vimos al comienzo de estas páginas, es un concepto "difícil", y la revelación de su máxima dificultad se manifestó a partir del efecto D. Esto permitió a los filósofos contemporáneos aprovechar que en ese momento el tema del arte pasaba de ser un problema que hasta entonces había exigido un conocimiento genuino de la práctica artística y de sus productos, a ser un problema por discutir, antes que nada, en el terreno de la filosofía, es decir en términos de la lógica del concepto correspondiente. Invirtiendo ese criterio, voy a postular que el error metodológico consiste en excluir la posibilidad de que el estado del arte luego del efecto D, en lugar de ser un momento más de la serie que debe ser incluido entre los casos por definir, sea una situación excéntrica, o teratológica, que solamente podemos explicar desde una teoría que pueda dar cuenta de toda la historia previa del arte. Si aceptamos esa posibilidad, debemos trabajar en una dirección que requiere hipótesis de diferente nivel y diferentes campos disciplinarios.

En lo que sigue trataré de exponer muy esquemáticamente una teoría en la cual es indispensable referirse a hechos (para evitar toda disputa sobre qué quiere decir esta palabra en nuestro campo, usaré el término "hechos" en el sentido de interpretaciones consensuales de hechos) y a interpretaciones de hechos (en el sentido de interpretaciones más problemáticas y/o inusuales). Mi intención, en este esquema, no es defender esas proposiciones con contenido empírico (aunque en otros contextos sí me interesa defenderlas), sino mostrar que hay una forma de tratar el problema de la definibilidad del arte que escapa a las dos grandes objeciones que pueden hacerse a las concepciones en boga: la objeción de que no nos proporcionan una definición genuina, y la de que operan como legitimadores implícitos de la situación de hecho de las artes contemporáneas. 
Las tesis que resumen ese punto de vista, formuladas en párrafos separados para subrayar su esquematicidad, son las siguientes:

1) Pese a las dificultades que presenta el concepto 'arte', desde la antigüedad (por lo menos desde Aristóteles) se constituye una denotación del mismo que abarca las distintas artes y que, sobre la base de tipos de objetos identificables (esculturas, pinturas, tragedias, epopeyas, comedias, diversas formas de música, de lírica, de danza), da un criterio de identificación suficiente para evitar dificultades mayores en el uso; sin embargo, eso no bastó para imponer un nombre como término específico para toda la clase. Aristóteles, además, propone algo parecido a una definición que unifica la clase mediante propiedades observables de los objetos (que les permiten ser miméticos), funciones (la producción de deleite, la producción y la contemplación de mimesis, y, en algún caso, la eficacia de la catarsis) y origen común (propensión innata a la mimesis).

Es razonable buscar el fundamento de esta primera producción del concepto ya sea en las características del arte de su tiempo (que representan, en particular en lo que respecta a las artes visuales, una revolución inédita en la historia) y/o en causas que determinan tanto ese surgimiento de la teoría como en el surgimiento del arte mismo.

2) A lo largo de la historia, las artes así reunidas no dan lugar a una actividad teórica sostenida que esté preocupada por conceptualizarlas en su unidad dentro de la diversidad de especies, calidades, culturas, estilos, épocas, clases sociales. Sin embargo, tal ausencia es suplida, por un lado, con referencias tópicas que se inspiran en el pensamiento clásico y reinterpretan libremente esas fuentes; por otro lado, con lo que voy a llamar (introduciendo un término que creo indispensable aquí) "conceptos prácticos" del arte, que fragmentan y colorean con las más diversas connotaciones lo que la primera síntesis aristotélica legó como un horizonte teórico dentro del que se maneja, con todas las hibridaciones que se quiera, el discurso letrado. Por "concepto práctico" entiendo el conjunto de actitudes, valoraciones, enunciados y usos que, por una parte, los productores, y, por otra, los consumidores, usuarios o receptores (pertenecientes a distintos grupos sociales), hacen de cada uno de los diversos tipos y niveles de entidades que ahora llamamos objetos u obras de arte. Una investigación acerca del concepto práctico de arte y su relación con los tópicos letrados sobre el arte es un terreno en gran medida virgen, en particular en lo que respecta a mostrarnos cómo se va construyendo el concepto de arte desde el Renacimiento.

3) El desarrollo de la modernidad burguesa, desde fines del siglo XVIII, que en el arte se manifiesta con la tantas veces invocada autonomía, representa la liberación del artista respecto de dependencias y patrocinios. El artista 
es lanzado al mercado, que le ofrece las opciones extremas de atenerse a las exigencias de la demanda o a la libertad ilimitada de ofertar lo que él decida producir, y también todos los grados intermedios. Por primera vez en la historia (y este hecho notable no ha sido, creo, señalado), a lo largo del siglo XIX hay dos tipos de arte culto, uno de los cuales expresa la voluntad del artista de decidir cuál es el sentido del arte. Esta corriente está unida no solamente al principio de que el artista es el dueño de su arte - y el que decide lo que vale en el arte-, sino también a la idea de que existe una cualidad específica, independiente de servidumbres y funciones adventicias (idea que se impone precozmente en la poesía simbolista), que corre como una línea unificadora en las artes visuales de toda la historia. Esa línea - que se expresa también en algunas corrientes de la historia y la teoría del arte- es la que culmina construyendo, en el siglo Xx, un concepto completivo del arte que incorpora la producción de las artes aplicadas o industriales, de las artes tribales, del arte de los niños, los enfermos mentales y hasta de los simios.

4) La apropiación del arte por los artistas (desde luego, muy relativa en los hechos, pero muy fuerte en la aspiración y las ilusiones de los artistas) es, en cierto modo, la de la reapropiación de las condiciones iniciales del arte: el juego de actividades que comprometen capacidades expresivas, simbólicas y cognitivas innatas ejercitadas por el disfrute de su ejercicio o de sus productos. Tales prácticas fueron interpretadas dominantemente en el marco de filosofías idealistas, para las cuales las artes en su conjunto, ya sea como espejo o como lámpara — para insistir en la imagen de Keats-, aparecieron como una forma peculiar, y quizá superior, de conocimiento, que se confunde con la mística en el caso de los poetas románticos alemanes, supera la separación entre filosofía y religión para los jóvenes filósofos alemanes amigos de aquéllos, y, ya decretada la muerte de Dios, sustituye la religión para Nietzsche y Mallarmé. Pero esta sustitución es también la culminación de la máxima autonomía y de la pretensión extrema de pureza y especificidad; una especificidad y una pureza nada fáciles de definir en la poesía y que, más tardía y contradictoriamente, se definen en las artes visuales (en las que, a lo largo de la primera mitad del siglo XIX, sólo Hegel y Baudelaire parecen tener idea del peculiar quid de la pintura). A fines de ese siglo, luego de la paradoja del impresionismo (que en nombre de un hiperrealismo retiniano termina haciendo de la pintura pura música cromática, casi abstracta), el arte entero se mira desde un punto de vista que extrae de él sólo lo que considera libre de todas las dependencias que se le impusieron a lo largo de la historia, sofocando u ocultando una supuesta especificidad.

Dos ideas centrales, ambas insostenibles, acompañan esa extraordinariamente fértil revisión de las artes visuales. Una de estas ideas es la de 
atribuir un carácter desnaturalizador a las diversas dependencias que le fueron impuestas al arte en el pasado, utilizándolo como instrumento de ciertas funciones (religiosas, ostentatorias, mágicas, didácticas, sometedoras, persuasivas, propagandísticas, de diversión o solaz, de integración social en el grupo, de organizadoras del ritmo en el trabajo colectivo, de distinción jerárquica). La otra idea consiste en reducir la especificidad de lo visual a las propiedades formales entendidas como propiedades perceptivas o Gestalten: armonías, ritmos, relaciones de proporción, etcétera.

Aunque acompañada por una teorización muy endeble, la transformación de la mirada en la primera mitad del siglo xx fue revolucionaria y dio lugar a un concepto de arte que no se limita a estilos ni épocas. Un emblema de tal cosa fue la entrada triunfal del arte africano, que primero se mudó de los gabinetes de curiosidades de los siglos XVII y XVIII a las colecciones etnográficas en el XIX, y de éstas a las galerías de arte en las primeras décadas del $\mathrm{xx}$.

5) Esta concepción de la pureza del arte obligó a dos o tres generaciones a mirar las obras con los ojos de los artistas, colocándose en su punto de vista, por lo menos en la medida en que un interés genuino - es decir, nada esnob- les permitió, a partir del contacto con las obras del pasado y del presente (no a partir de lecturas y doctrinas), adquirir una percepción adiestrada en el reconocimiento de los problemas de la producción que es posible descubrir en la recepción. Esa peculiar comprensión del arte fue el núcleo del "concepto práctico" del arte de lo que, para evitar equívocos de nomenclatura, voy a llamar, de manera incluyente, la "vanguardia modernista".

Pero la doctrina también existió. La función estética pura en las artes visuales quedó reducida, en su versión ad usum delphini que recorrió el mundo, al deleite sensible ante cierta armonía, o, en su versión más reflexiva, a posturas como las de Bell, Fry, Apollinaire, Gleizes-Metzinger, o luego Greenberg. Unos cuantos artistas formularon un pensamiento mucho más rico y próximo a su concepto práctico, pero su influencia fue insignificante (sólo dispusimos del conjunto de los notables escritos de Klee en 1956, mientras que Torres García es visto durante mucho tiempo como un outsider periférico). Ese formalismo superficial sirvió para que muchos de los que antes podían divertirse observando los ropajes representados en los cuadros añejos, o el logrado parecido de un retrato, adquirieran un discurso con el cual justificar su forzada asistencia a una exposición.

6) Esa inmensa mutación cultural en la que coinciden, por un lado, la visión artística de la vanguardia modernista y el concepto práctico correspondiente, y, por otro, un concepto formalista explícito, letrado, que forma lo que podemos llamar la teoría elemental o estándar de esa vanguardia, está 
acompañada de otros elementos significativos. En particular, de la exaltación de lo moderno (de la que Baudelaire es un adelantado), la voluntad de subversión y de crítica antiburguesa del artista (que desde principios del siglo XIX marca la nueva situación social del artista a la intemperie del mercado) y, por otro lado, la arrogancia del artista como dueño de decidir qué es el arte, que se va abriendo paso desde el siglo anterior.

Este conjunto explica lo que he llamado "el efecto D". Se trata de un caso que creo notable como ejemplo de cómo pueden cruzarse series causales independientes que tienen, de todos modos, una alta probabilidad de encuentro. Cuando ocurre este encuentro de las series independientes con alta probabilidad de cruce surge un hecho singular que tiene la particularidad, que parece contradictoria, de ser imprevisible pero a la vez sumamente probable.

Según estos supuestos, el efecto D surge cuando un artista singular, interesado en las letras y en las ideas, que no es realmente partícipe entusiasta de la nueva mirada (en el momento en que los más grandes artistas del siglo están embriagados de entusiasmo y empuje a medida que descubren la riqueza de esa mutación), con desgano, y con alguna destreza epidérmica, intenta producir, sucesiva y epigonalmente, impresionismo, simbolismo, fauvismo, expresionismo y cubismo. Pero en la misma medida en que está lejano del "concepto práctico" propio del arte moderno y acepta a pie juntillas que el concepto letrado corresponde a la justa comprensión del arte, su nunca desmentida inteligencia le revela la pobreza insalvable de un arte que aparece como puro disfrute de los sentidos. Agotada la (para él) trivial y "olfativa" pintura de la vanguardia modernista, los terrenos de investigación incitantes de los que dispone no pueden ser otros que: (a) la pesquisa de lo nuevo como un valor por sí mismo; (b) la tarea del artista como desafiante provocador y escarnecedor del filisteo; (c) la pintura como ejercicio del pensamiento, la imaginación y el lenguaje en competición con la poesía; d) el ejercicio del derecho de propiedad del artista sobre la naturaleza del arte, camino en el que quedaban todavía algunos pasos para llevar esa apropiación a su límite extremo del jus abutendi. Podríamos decir, con cierta exageración pedagógica, que el efecto D no es otra cosa que esa conjunción.

7) Lo anterior es la descripción del concepto práctico que del arte constituyó la vanguardia modernista. Pero ese concepto práctico de la vanguardia modernista comporta, por su parte, una reconstrucción del concepto del arte en toda su historia, que no sólo modifica en alguna medida su connotación, sino que, sobre todo, difiere de los conceptos doctrinarios explícitos que integraron esa historia. Estamos pues, por una parte, ante la ampliación extrema de la denotación de ese concepto y, por otra, ante la debilidad del concepto letrado que reduce a meras cualidades formales perceptivas 
las propiedades necesarias y suficientes que definen el concepto. Está claro que si admitimos que la amplia denotación del concepto práctico es una adquisición que queremos preservar, tenemos que abandonar el concepto letrado y recuperar y reconstruir teóricamente el concepto práctico del arte que impuso la vanguardia modernista, y que permitió configurar esa denotación. Eso comporta plantearnos, justamente, la definición del arte que sea capaz de dar cuenta de esa denotación. Se trata de un problema que por el momento evita discutir la segunda ampliación del concepto que resulta (o parece resultar) del efecto D. De todas maneras sabemos que, aun así acotado, el concepto 'arte' sigue siendo "difícil".

8) En la empresa de plantearnos la definibilidad del arte, la cuestión primera es decidir si ese complejo de prácticas, funciones, obras, facultades o pulsiones innatas, que nos ofrece como referentes el concepto de arte tal como lo usamos a lo largo de la primera mitad del siglo XX — cuando el efecto D no había modificado sustancialmente el mundo del arte, y mucho menos había conmovido a los filósofos-, puede ser interpretado como otra cosa y no como una agregación o conglomerado de facto. Ya indicamos que tal complejidad (menor, desde luego, en todas las culturas anteriores a la revolución modernista) no fue obstáculo para la identificación práctica del arte.

Pero está claro que esa aparente identificación práctica esconde el riesgo de que lo que se identificaba en cada caso fuera una colección de objetos análogos, pero cada uno de ellos con sentidos, funciones y usos distintos. Esto lleva a la discusión, ya larga y enredada de varias maneras, acerca de la legitimidad de las interpretaciones de culturas ajenas leídas con los supuestos de una cultura propia, y, en particular, nos plantea la legitimidad de la lectura estética de ciertos objetos que, quizá sin derecho, llamamos obras de arte de culturas "otras". Es posible argumentar que nos ha sido posible usar esos objetos de culturas "otras" sin forzarlos. Y tanto es así que podríamos decir, más bien, que han sido esos objetos los que nos han forzado a reconocerlos y usarlos como arte. Por otra parte, el buen sentido nos dice que si encontramos algo que cierto pueblo utiliza como insignia de poder y que además es una brújula (aunque ese pueblo tiene todo el derecho de hacer lo que quiera con las brújulas), no por eso admitiremos con facilidad que tienen razón al afirmar que el uso que le dan corresponde a la historia de ese objeto, y al cómo y al por qué ha sido producido. Y si nos enteramos que ellos mismos lo han construido, aunque insistan en que para ellos es una insignia de poder, lo más probable es que, por alguna razón, quieran ocultar u ocultarse el uso primordial del instrumento.

No cabe duda de que el sistema cultural en el cual operan diferentes obras de arte en diferentes culturas no es el mismo, y en ese sentido nos estaría prohibido sacar de cierto arte, entendido a nuestra manera, 
conclusiones para esa cultura; pero no debe prohibirse extraer de esas culturas objetos de arte para entenderlos a nuestra manera, puesto que no es razonable pensar que el objeto pueda ser visto como tal solamente por una casual coincidencia de sus propiedades con nuestras expectativas.

Es posible sostener, de un modo algo paradójico, que la tesis purista del arte, en su versión formalista - aunque a ella se atribuya, con razón, un papel importante en la ampliación del concepto arte con la incorporación de las artes tribales-, es la que también propicia la resistencia a admitir la legitimidad de considerar obras de arte a esas mismas artes tribales. Porque es precisamente el formalismo el que opone lo específico del arte a las funciones heterónomas, y contamina con ese supuesto las concepciones que, respetuosas de una "cultura otra", niegan que ciertos objetos de esa cultura puedan ser vistos legítimamente como obras de arte. Pero esa negativa empobrece esa cultura si nos quita el derecho a disponer, como obras de arte, de ciertos productos de la misma; le quita a esa cultura una dimensión que no es insignificante

9) La ampliación del concepto 'arte' de modo que denote un universo variadísimo de entidades que un siglo antes podían llamarse ídolos, fetiches o utensilios, fue acompañada, en el caso de las artes visuales, de la pretensión de realizar obras que manifestaran solamente esa especificidad, proceso que también se planteó con la poesía lírica y, en menor grado, con las demás formas de arte. Adoptar tesis formalistas permitió postular algunas propiedades necesarias y suficientes para que un artefacto fuera considerado una obra de arte con independencia de su ubicación en la cultura de la que proviene. Pero un examen mínimo de todo aquello que abarca el concepto modernista del arte parece indicarnos que los aspectos estrictamente formales de un objeto visual no son ni necesarios ni suficientes, y que una definición formalista trivializa completamente el concepto práctico del arte que produjo la vanguardia. Desde luego, es posible entender por propiedades formales todo aquello que puede invocarse como sentidos y calidades propiamente artísticos de una obra, pero entonces el término "formal" quiere decir lo mismo que "artístico" y la definición del arte se vuelve tautológica en el sentido más trivial.

La dificultad es que todo parece indicar que no es posible proponer otra definición (al menos del tipo tradicional) con mejor suerte que la que podemos tener con ésta. La denotación del concepto de arte, propio de la vanguardia modernista, es lo suficientemente variada como para que no haya, para ella, una definición esencial. Hacer que la calificación de la obra repose en cierta experiencia experta llevó naturalmente a los buenos receptores (a veces críticos de excelente ojo) a presumir que el tipo de experiencia calificadora del arte supone el reconocimiento del quid artístico 
que la hace ser una obra de arte, como si las experiencias singulares que culminan, todas ellas, con la aprobación o la admiración (o el rechazo) tuvieran cierto tipo de cualidad que debía responder a las cualidades perceptibles que sirven para definir el arte. Si esto no es así - y efectivamente no parece ser convincente ninguna definición esencial del arte de las que se han propuesto, y menos con la incorporación de la vanguardia modernista y su concepto ampliado del arte-, debemos plantearnos una manera de definir el arte que no consista en disponer de notas esenciales que se refieran a la función, a las propiedades observables de las obras, o a cierto núcleo invariable que responda a las condiciones iniciales que están en el límite entre el equipamiento neurológico y la práctica social. El camino debe ser otro.

10) Creo que debemos renunciar a una definición en el sentido tradicional. El punto de vista que propongo parte de que no estamos frente al problema de reconocer si un elemento es o no integrante de una clase, sino de reconocer si una entidad es parte de una serie o de un proceso. La primera cuestión es, entonces, cómo identificamos algo como un proceso, cómo lo diferenciamos como evento singular, como una sola historia, es decir, como un individuo. Podemos formular esto de una manera popperiana, diciendo que cada una de las actividades o instituciones son entes históricos y son, como el mismo proceso de la historia en su conjunto, un hecho único. Está claro que, en este caso, los problemas pueden complicarse, porque el proceso de la historia global, tenga los cambios que tenga, no ofrece problema de identificación. Ocurra lo que ocurra en el proceso de la historia de la humanidad, ese nuevo momento integrará la historia. En cambio, en este caso, la dificultad consiste en que el proceso que nos interesa no tiene previsibilidad; es abierto, pero no abarca todo evento posible; por lo tanto, para identificarlo parece necesario disponer de un criterio para decidir si un nuevo suceso forma parte o no del proceso en cuestión. Creo que si tenemos alguna razón convincente para considerar que ese proceso es identificable como una singularidad diferenciable de lo que ella no es, las razones de esa identificación deben operar como criterios para decidir, de un modo no convencional ni arbitrario, si cierto evento forma parte del proceso. El tipo de definición -o de identificación- que propongo, parte de que el arte es un proceso en el que la identificación del ente es realizable de manera análoga a la que se puede hacer cuando hablamos, por ejemplo, de un ser vivo que sufre ciertas metamorfosis. Pero es obvio que, en el caso de las series del tipo gusano-crisálida-mariposa, esa identificación está determinada por ciertos límites espaciales en los que ocurre una transformación gradual, por cierta secuencia típica, y por la conservación de un sistema que tiende a conservarse y a reproducirse. Es evidente que las dos primeras características no 
pueden invocarse respecto del arte ${ }^{6}$ veremos luego cuál es la situación de la tercera.

11) En este punto tenemos que establecer las condiciones que nos permitan decidir si un conjunto de sucesos es un proceso (o una serie), o si se trata simplemente de una sucesión que sólo por tradición, por convención o por cualquier otra razón de hecho, es considerada como una entidad identificable. En algunos casos, la identificación se basa en criterios fuertes. Una sucesión puede ser entendida como una serie (si resulta de la existencia de un patrón lógico), o como un proceso (si proviene de una programación que selecciona y ordena ciertas causas en función de un determinado proyecto). Una progresión aritmética sería el ejemplo más simple del primer caso, y una serie de matrices del conocido test de Raven (o similares) para la medición de ciertas capacidades intelectuales de abstracción nos proporciona un repertorio variado del mismo tipo.

Los procesos, en cambio, tienen una estructura causal y no puramente lógica. No cabe duda de que el desarrollo de un gusano que termina siendo mariposa es un proceso identificable, singular, y que, como vimos, no es necesario pensar en una esencia para hacer la identificación. Pero el supuesto filosófico de esa esencia está detrás de la investigación de las condiciones causales que aseguran la reiteración de esa secuencia que culminó en el conocimiento de que existe un programa que rige el proceso causal, y que el hecho singular es un caso de cierto género: el de los procesos regidos por programas idénticos (o casi idénticos).

Un proceso también puede ser identificado como un hecho singular cuando consiste en un sistema cerrado en el que su falta de intercambio de materia y energía con el exterior nos asegura la identificación del proceso a partir de la conservación de ciertas magnitudes.

Ahora bien, en la medida en que lo que llamamos el proceso del arte no consiste ni en una serie con un patrón lógico, ni en un proceso predeterminado (por algún genoma, programa o proyecto), ni en el proceso constituido por la actividad que ocurre en un sistema cerrado (que es previsible cuando conocemos las leyes involucradas), parecería imposible justificar la sucesión de los eventos que lo constituyen como un proceso identificable. Salvo que podamos proponer otro tipo de proceso identificable del cual el arte sea un caso. Quizá el único.

12) Los criterios que solemos utilizar para considerar que cierta entidad individual, del tipo del objeto material, mantiene su identidad a través del tiempo pueden ser de varias clases; pero, en general, son casos más o me-

\footnotetext{
${ }^{6}$ Es obvio que está determinada también por un plan genético, pero no es necesario conocer ese aspecto "esencial" para aceptar cómodamente la individualidad y la identificación del proceso: la localización espacial del proceso y el mantenimiento de un organismo que "funciona" son suficientes para pensarlo como una entidad singular.
} 
nos toscos de hipótesis esencialistas - como ocurre con el clásico cuchillo al que se le van cambiando el mango y la hoja- en los cuales perdura una identidad que no es la del objeto singular, sino la de la estructura (o la del tipo, y no la del caso). De todos modos, como lo sostiene Kripke (1981), la identidad es a veces vaga y puede, entonces, llegar ser intransitiva. Pero si hablamos de la identidad del proceso del arte es justamente para escapar a la obligación de proponer una definición esencial imposible.

Sustentaré, en cambio, que es razonable considerar que el proceso será siempre el mismo proceso (un determinado proceso singular) aun en el caso de transformaciones que pueden ser radicales, pero que, por alguna razón, están ligadas fuertemente al conjunto de los eventos. Creo que esa ligazón interna, que no comporta el reconocimiento de una esencia ni de un programa de desarrollo, puede darse cuando el proceso es capaz de producir y reproducir luego cierto orden; es decir, cuando a lo largo de ese proceso se producen configuraciones o sistemas viables, con capacidad de subsistir, que no dependen de un sistema externo capaz de imponer o mantener ese orden. Está claro que, en cuanto que el arte está al servicio de funciones sociales heterónomas, lo que genera ese orden puede atribuirse al proceso de selección que comporta todo aprendizaje o toda puesta a punto de un instrumento. En ese sentido, la identidad del arte sería un resultado de su dependencia de otra institución que le impone una finalidad, la modela para ella y la define por ella. Pero es posible suponer (luego veremos que se trata de una hipótesis bastante bien fundada) que por debajo de esas funciones (pero precisamente porque las cumple), el arte produce también configuraciones específicas como resultado de ciertos encuentros o cruces de series causales a partir de los cuales sobreviven estructuras viables. Esas configuraciones no son viables (o no son solamente viables) como resultado de la selección determinada por la capacidad de cumplir las funciones heterónomas, sino porque esas configuraciones crean o ponen de manifiesto necesidades ignoradas que, al ser satisfechas, tienden a fijar dichas configuraciones. De este modo se podría explicar la aparición de un orden obtenido de manera selectiva, que consiste en un instrumento que se crea junto con la necesidad cuya satisfacción asegura la supervivencia del instrumento. Esto no es una solución verbal: basta con que (a) la configuración $x$ sea activadora de una necesidad dormida $z$ y a la vez medio de darle satisfacción, y (b) la configuración $x$ no resulte de un programa preexistente asociado a $z$, sino de un encuentro aleatorio de series causales, una de ellas asociada a la función heterónoma. La exigencia de que $x$ no resulte de $z$ es necesaria porque, de otro modo, lo más tentador es considerar $x$ como resultado de un mecanismo programado que existe en el nivel psiconeurológico del sujeto humano, y con ello el arte se vuelve una serie de instancias de desarrollo programado de manera innata, lo que poco tiene que ver con la complejísima historia social de su desarrollo, en 
la que se suceden novedades diversas. Para la clásica discusión entre concepciones sociologistas y concepciones "puristas" o "formalistas" del arte, esta propuesta resulta paradójica porque ella sostiene que es necesaria la acción de causas externas a las prácticas que llamamos artísticas para explicar la existencia de novedades que siguen integrando un proceso singular, identificable y conceptualizable a pesar de la variedad.

Por otra parte, no es difícil descubrir que también estoy utilizando aquí un esquema que proviene del neodarwinismo, y que es el único dispositivo teórico que permite explicar la aparición de novedades en un sentido fuerte, es decir, que no resultan de un programa previo. Una novedad de este tipo supone continuidad conceptual - porque sólo hay novedad dentro de cierto universo de entidades-, pero, a la vez, una ruptura con el concepto previo, porque la novedad debe escapar, de alguna manera, a las reglas que regían hasta ese momento la producción de esas entidades, o a los criterios mediante los cuales se las reconocía. Pero los organismos que se transforman escapan a esa disyuntiva porque la novedad ocurre como ruptura que permite la continuidad; incluso la creciente complejidad y funcionalidad del sistema ocurre como resultado del encuentro de los propios mecanismos internos, que generan transformaciones aleatorias, y de series causales independientes, externas, que seleccionan en términos de alguna forma de eficiencia funcional.

En la muy variada denotación que comporta el concepto modernista de arte podemos encontrar una sucesión significativa de surgimientos que tienen una fuerte organización y que son sólo causalmente dependientes de las funciones explícitas y heterónomas, pero que, muchas veces, no están al servicio de éstas, ni las expresan, ni mantienen con ellas ninguna homología. Si esto es así, entonces el proceso del arte no puede ser visto como una sucesión de eventos asociados de facto, y su identificación como proceso singular puede ser algo más que el resultado de una convención o una tradición. Una sucesión de eventos que puede ser descrita como lugar en el que surgen configuraciones o sistemas capaces de reproducirse no es un mero conglomerado. La biografía del arte nos hace descubrir que, por debajo de una historia que parece aluvional, han ido apareciendo puntos muy notables de organización, en la que parece ocurrir algo así como el aprovechamiento de encuentros casuales para un desarrollo del sujeto social humano en una dimensión a la cual me referiré luego.

13) En lo que sigue voy a indicar cuáles son los encuentros en los que brotan formas significativas de organización que señalan en la historia del arte inflexiones muy marcadas y que estructuran también esa historia, no como una secuencia, sino como un conjunto de prácticas y productos interrelacionados de manera peculiar. En otras palabras, voy a retomar el esquema anterior de lo que podemos llamar la "lógica" del concepto 'arte' 
para ver cómo funciona aplicado a la historia, o mejor, a lo que podríamos llamar la "biografía" del arte.

Debemos partir de las condiciones iniciales del arte. Me refiero con esto a las conductas básicas, sin las cuales el proceso no habría tenido lugar, y que es necesario ubicar en el mundo social primitivo de un hombre neuropsicológicamente muy parecido a nosotros, conjeturas inevitables y obvias, que me interesa rememorar porque creo que es posible usarlas de cierta manera.

Esas condiciones iniciales son de naturaleza diversa, y en su diversidad está la posibilidad de engendrar novedad al permitir que ya entre ellas, en un nivel casi presocial, ocurran encuentros productivos. También su diversidad permite que estas condiciones iniciales aparezcan asociadas como medios o complementos de muchas otras actividades con funciones definidas. Un rasgo importante de esas actividades es que corresponden al nivel simbólico, y que no participan de las funciones vitales perentorias: son juegos simbólicos, para usar la terminología piagetiana, y también algunos otros con raíces filogenéticas más remotas, pero todos ellos de tipo residual o vestigial, o intersticial o excedentario. Algunos de ellos están centrados en el uso de algunas facultades por el puro placer de su reconocimiento y exploración. Me estoy refiriendo, por ejemplo, a la convergencia forzada de los ojos a los efectos de dar lugar a imágenes dobles, al juego con el lenguaje para obtener sinsentidos, palabras invertidas que se encadenan y reordenan al repetirse o asociaciones fonéticas, y también a los juegos con ritmos sonoros y con ritmos gráficos, a la diversión que produce la mímica, a la mimesis gráfica o modelada, etc. Es interesante señalar que estas raíces lúdicas del arte son generalmente juegos con las facultades cognitivas y, en ese sentido, es posible considerar que, desde sus fuentes, el arte forma parte del autorreconocimiento que el sujeto hace de todos los niveles de su actividad. Pero hay formas más primitivas, como el gusto por las cualidades sensibles disfrutables sin consumo; en particular, cualidades visuales y táctiles que perduran indefinidamente en los objetos: brillo, color, pulimento, que dan lugar a la manipulación, el atesoramiento y, eventualmente, la atribución de otros valores o funciones capaces de justificar colectivamente el interés o la significación del objeto.

Voy a tratar de ejemplificar la capacidad de encuentro generador de nuevas prácticas que tienen todas esas actividades protoestéticas que he llamado condiciones iniciales. Para ello debemos considerarlas en el nivel idiosincrásico, individual, en el momento en el que existieron en la zona limítrofe y de interacción entre, por una parte, la evolución biológica y, por otra, las condiciones que agrega a los mecanismos de selección natural el desarrollo de capacidades que tienden a fijarse gracias a una selección en la que interviene el selector y multiplicador social. 
Hay dos ejemplos significativos. Uno de ellos es el encuentro de los ritmos motrices y las buenas formas visuales, dos sistemas independientes que se encuentran y colaboran. Una vez que el sujeto es capaz de trazar ritmos en forma gráfica, puede percibir, controlar y disfrutar ese rastro perdurable que proviene de áreas corticales motoras y que proporciona patrones adecuados para la actividad de reconocimiento y el efecto placentero en las áreas sensoperceptivas. Se trata del surgimiento de una capacidad compleja y nueva que no está montada en el sistema nervioso, ni surge de maduraciones, sino que se constituye en la actividad externa. Otro ejemplo de estos montajes es el que podemos considerar como la fusión de dos condiciones innatas, independientes, en la formación de la capacidad de representación gráfica. Se trata de la capacidad mímica (que hay buenas razones para sostener que es innata también en su manifestación gráfica) ${ }^{7}$ y los ritmos, tal como se registran en el trazo y se reconocen visualmente. Se trata de dos capacidades que corresponden a unidades neurológicas independientes y que se encuentran en el espacio del juego gráfico, y dando lugar a una representación que es a la vez mimética y rítmica.

14) Pero hay un lugar de encuentro de series independientes que marca el nacimiento del arte como hecho social. Las que he llamado "condiciones iniciales" adquieren carácter social solamente en la medida en que éstas queden injertadas en una práctica social preexistente y funcional. Eso es así inevitablemente, dado el carácter socialmente no funcional que distingue esas conductas idiosincrásicas y privadas. Lo que reconocemos en la historia como aspecto o parte específicamente artística de otra práctica que la subordina, o, en la modernidad, como práctica específica en el marco de una institución autónoma, es el resultado de esa socialización, y esa socialización requirió, necesariamente, la sujeción de esas condiciones iniciales a otra práctica ya instaurada socialmente.

La heteronomía del arte ha sido una bête noire desde el siglo XIX. Voy a infringir esa ya larga tradición sosteniendo que dicha heteronomía es la condición sin la cual las prácticas excedentarias, individuales, sin posibilidad de una acumulación o construcción histórica, consiguen desarrollarse y generar una serie de novedades de creciente complejidad o riqueza. Efectivamente, como parte de la religión, la magia, el boato, la educación, la función de persuadir o intimidar al servicio del poder, la diversión, o lo que fuere, esas prácticas miméticas, expresivas, rítmicas o vagamente exploradoras de las capacidades cognitivas y comunicativas, quedan obligadas a sistematizarse y servir a fines, se vuelven técnicas (es decir, artes en el sentido inespecífico de la palabra). Lo interesante es que sus éxitos téc-

\footnotetext{
${ }^{7}$ La naturaleza innata de la capacidad de representación gráfica de las formas de los objetos reales, entendida como un caso particular de la aptitud mímica, es una hipótesis en cuyo favor hay buenos argumentos (Fló, 1989).
} 
nicos generan descubrimientos excedentarios, que no corresponden a los fines que podemos llamar heterónomos, sino que, en sus formas más simples reproducen, en un nivel superior de complejidad, el carácter autosuficiente de las condiciones iniciales. No voy a proponer aquí un inventario - que podría ser extenso- que dé cuenta de cómo la dependencia del arte respecto de instituciones y funciones heterónomas genera los más ricos, complejos e interesantes niveles de lo que forma parte de su especificidad. En las artes visuales, uno de esos casos es el de la investigación técnica que transforma la mimética gráfica hasta volverla representación de un espacio luminoso tridimensional. Esa técnica -en sí misma una destreza al servicio de la documentación ilusionista, tan eficiente para fines prácticos como el uso documental de la fotografía- fue, a su vez, imposible (por razones que no puedo invocar ahora) sin el desarrollo de una refinadísima invención rítmica y armónica, que podemos llamar poética para sugerir rápidamente un sentido que alude a una cualidad, y que, por lo tanto, no puede ser descrita sino simplemente evocada en quienes la han experimentado. El puro academicismo fotográfico no es el principio, sino la degradación tardía de esa invención.

Pero la mayor conquista específica que resulta de esa situación servicial del arte bajo su larga vida heterónoma es hacer de él la autorrepresentación del sujeto humano individual; una autorrepresentación que no resulta de recursos privados del sujeto neurológico, sino que requiere una construcción social simbólica que retorna al individuo y lo dota de los medios que permiten el autorreconocimiento. De muchas maneras, los artistas, y en particular los poetas y narradores, han tenido conciencia de que ése es el sentido específico de sus obras. Menos clara es tal cosa en el terreno de las artes visuales, pero creo, aunque no es del caso argüir ahora en esa dirección, que ese sentido es propio de todas las artes en el mismo momento en que dejan de ser diversión o solaz para volverse el producto de una actividad histórico-cultural constructiva.

Los aspectos específicos que se van construyendo a lo largo de esa historia son impuestos, de alguna manera, por la heteronomía del arte, es decir, por el cruce de series causales independientes, y no por un desenvolvimiento interno de esa especificidad, que, para ser admisible, exigiría cargar con el alto costo de una metafísica teleológica. Una fórmula de aire paradójico resume bien mi pensamiento: los grandes hallazgos que le van dando al arte sucesivos niveles de especificidad son, en gran medida, resultado de su heteronomía. Está claro que esas especificidades, de las que el artista es consciente en algún grado, no son necesariamente conscientes en la versión común que del arte tiene una sociedad. Pero ése es otro problema.

15) Creo importante insistir en que la especificidad del arte no es, por cierto, lo que las condiciones iniciales proporcionan (juego, diversión, ac- 
tividad autotélica), ni es lo que la presión heterónoma impone como fines de una técnica al servicio de ciertas funciones o instituciones sociales, sino lo que resulta de ese encuentro. Y lo que resulta de ese encuentro no solamente es la historia de ciertas técnicas heterónomas, sino, también, otra historia paralela de hallazgos y conquistas específicas. En muchos aspectos, estas conquistas son sólo variaciones, pero también, a veces, son mensurables como ampliaciones o crecimientos acumulados y, por lo tanto, marcan un sentido a esa sucesión. He señalado ya, como identificador privilegiado de las artes en general y en particular de la literatura, la construcción de una representación del sujeto, que socializa la subjetividad.

Una propuesta de este tipo supone -más que una definición- la identificación de un proceso con un determinado sentido. Un proceso en el que las transformaciones más notables (y que han tenido efecto replicador sobre las instancias posteriores de ese proceso) han sido modos más complejos y refinados del autorreconocimiento del sujeto. Pero no es admisible suponer que las notas necesarias y suficientes para determinar si una obra es arte o no son las que indican que colabora, por ejemplo, en ese autorreconocimiento, aunque éste fuese vertebrador del proceso del arte. La mayor parte de las obras forman parte de constelaciones dentro de las cuales las obras tienen sus parentescos y son valoradas y reconocidas desde las claves que esa constelación ha impuesto de hecho.

Téngase en cuenta que la tesis que sostiene que el arte es un proceso singular, identificable por ciertas especificidades que se manifiestan a lo largo del mismo, es una tesis compatible con la que niega la existencia de rasgos necesarios y suficientes que permitan definir si cierto objeto es o no parte de ese proceso. Que una obra pertenezca a la serie de los productos que integran ese proceso y sea evaluada de cierta manera depende de decisiones de facto propias de diversos poderes a lo largo de la historia. Pero no son las decisiones de esos poderes, o las "del mundo del arte", las que identifican ese proceso, sino las construcciones específicas que surgen de encuentros no proyectados y que introducen en ese proceso una causalidad interna al mismo. Sin duda, para que exista esa causalidad interna de lo específico en el desarrollo posterior del proceso, es necesario que por lo menos los artistas posean un concepto práctico del arte que incluya la conciencia de esas especificidades.

La observación anterior, en el sentido de que no todo producto del proceso del arte debe ser un ejemplo de las manifestaciones específicas que permiten identificar ese proceso, tiene su ejemplo extremo en los readymade. Es razonable suponer que esos objetos no han sido aceptados como arte solamente por la arbitraria decisión del poder del mundo del arte, sino que su aparición responde a una causalidad interna del proceso del arte, aunque de esa causalidad provengan obras que fueron propuestas y son leídas como revelación del carácter radicalmente convencional del arte. 
16) Quiero cerrar este sumario con una última observación. Es cierto que no disponemos de una definición que nos permita, mediante un procedimiento mecánico, decidir si algo es o no una obra de arte. Es cierto que la pertenencia de ciertos productos a la vida de esa entidad justifica en términos taxonómicos denominarlas "obras de arte", y, en ese sentido, se puede decir que el mundo del arte es el que decide que algo es una obra de arte al introducirlo en un circuito que forma parte de esa compleja entidad singular. Pero ninguna de esas dos afirmaciones en las que se ha hecho fuerte la reflexión filosófica contemporánea sobre el arte nos impide identificar el proceso a partir de sus formas de reproducirse y de ampliarse. Por otra parte, si bien la identificación del arte como un proceso singular y abierto no permite concluir que el arte es una práctica que debe perdurar para siempre, sí nos permite, en cambio, discutir acerca de si ciertas mutaciones del arte comportan un regreso a situaciones de juego idiosincrásico que se parecen a las que conjeturamos que son sus raíces más remotas. Una identificación del arte a partir de su biografía y los sentidos que ella nos indica nos permiten usar el conocimiento que tenemos de ese proceso (conocimiento intuitivo, en cuanto sujetos que formamos parte de esa entidad como productores o receptores del arte, pero conocimiento que, si esta teoría es aproximadamente correcta, debería reflejar ese nivel intuitivo). Éste es el punto en el cual esta propuesta difiere radicalmente de las que he considerado antes, en las cuales la cuestión se toma a partir de la mutación que han tenido las artes visuales en estos últimos treinta o cuarenta años, de tal manera que, una vez admitido que esa mutación integra legítimamente el proceso del arte, este proceso es o bien interpretado hegelianamente como dotado de un sentido, o bien considerado como un proceso de hecho en el que cada aparente legitimación de una obra es, en realidad, un decreto simplemente autoritario que se esconde bajo una pseudoargumentación.

Desde mi punto de vista, el efecto D es un efecto interno al sistema del arte, que aparece como un síntoma en cierto modo previsible en un momento en el cual la autonomía del arte ha generado una catarata de transformaciones. No cabe analizar aquí el modo como ese hecho limítrofe e irrepetible se transforma en un paradigma del arte contemporáneo. ${ }^{8}$ Pero sí parece posible, desde la identificación del arte que propongo, considerar que ese efecto D - que no debemos identificar con la obra y menos todavía con las ideas tardías de Duchamp - resulta en gran medida de decisiones del poder en la institución arte que dispone de algo así como un registro civil que expide documentos de ciudadanía. Es extraño que los

\footnotetext{
${ }^{8}$ Digo irrepetible, pero lo cierto es que es legítimamente continuable bajo la forma de una poesía de los objetos, o de una poesía mediante objetos, como la que desarrolló el mejor arte surrealista.
} 
filósofos próximos a una concepción institucionalista no hayan considerado el problema de la legitimidad del poder en el mundo del arte cuando ese mundo está controlado por el poder político en regímenes autoritarios, y - lo que es más grave, porque atañe a las situaciones dominantesque tampoco hayan considerado el problema análogo de hasta qué punto el poder está controlado por el mercado y por las políticas culturales estatales asistidas por expertos, que no pueden sino reflejar la situación de hecho del propio mercado. De ser así, la cuestión del concepto del arte solamente puede reverse si dudamos, al menos hipotéticamente, de que debamos amoldar el concepto a las características que tiene el arte actual.

\section{BIBLIOGRAFÍA}

Ahlberg, L.-O., 1993, "The Nature and Limits of Analytical Aesthetics", British Journal of Aesthetics, vol. 33, no. 1, pp. 5-16.

Bourdieu, P., 1992, Les Règles de l'art, Éditions du Seuil, París.

Bürger, P., 1984, Theory of the Avant-Garde, University of Minnesota Press, Minneápolis.

Danto, A., 1997, After the End of Art, Princeton University Press, Princeton.

— 1986 , The Philosophical Disenfranchisement of Art, Columbia University Press, Nueva York.

—, 1981, The Transfiguration of the Commonplace, Harvard University Press, Cambridge, Mass.

—, 1964, "The Artworld", Journal of Philosophy, vol. 61, no. 19, pp. 571-584.

Davies, S, 1991, Definitions of Art, Cornell University Press, Ithaca.

Dickie, G., 2001, Art and Value, Blackwell, Malden.

— 1984, The Art Circle, Haven Publications, Nueva York.

Fló, J., 1989, Imagen, icono, ilusión, Universidad de la República, Montevideo.

—_, 1957, "L'Art comme simple évaluation", en Atti del III Congresso Internazionale di Estetica (Venecia), Ed. della Rivista di Estetica, Turín.

Hofmannsthal, H. von, 1901, "Les couleurs", en Van Gogh. Ses contemporains, sa posterité, ed. Pierre Cailleur, Vésenaz, 1947.

Isenberg, A., 1987, "Analytical Philosophy and the Study of Art", The Journal of Aesthetics and Art Criticism, vol. XLVI, pp. 125-136.

Kripke, S., 1981, Naming and Necessity, Blackwell, Oxford [versión en castellano: El nombrar y la necesidad, 2a. ed., trad. Margarita M. Valdés, Instituto de Investigaciones FilosóficasunAM, 1995].

Levine, L., 1969, “The Artist Speaks: Les Levine”, Art in America, noviembre-diciembre, 1969, pp. 86-93.

Levinson, J., 1989, "Refining Art Historically", The Journal of Aesthetics and Art Criticism, vol. 47, no. 1, pp. 21-33.

— 1979 , "Defining Art Historically", The British Journal of Aesthetics, vol. 19, no. 3, pp. 232-250.

Mandelbaum, M., 1965, "Family Resemblances and Generalizations Concerning the Arts", The American Philosophical Quarterly, 1965, vol. 2, no. 3, pp. 219-228. 
Morawsky, S., 1974, Inquiries into the Fundamentals of Aesthetics, The MIT Press, Cambridge, Mass.

Weitz, M., 1956, "The Role of Theory in Aesthetics", The Journal of Aesthetics and Art Criticism, vol. XV, no. 1, pp. 27-35.

Recibido el 13 de diciembre de 2001; revisado el 1 de julio de 2002; aceptado el 23 de julio de 2002 